\title{
When a very fast radical probe cyclization hints at a carbanionic intermediate rather than at a radical one: a further proof of a polar mechanism for the aryl bromide-alkyllithium exchange reaction
}

\author{
Nicolas Bodineau, ${ }^{a}$ Norma S. Nudelman,*a Graciela V. García, ${ }^{a}$ Jean-Marc Mattalia, \\ Rogério Martins, ${ }^{b}$ Michel Arbelot, ${ }^{b}$ and Michel Chanon ${ }^{b}$ \\ (a) Departamento de Química Orgánica, Facultad de Ciencias Exactas y Naturales, \\ Universidad de Buenos Aires, Pabellón II, 3er. Piso, Ciudad Universitaria, 1428, \\ Buenos Aires, Argentina \\ (b) Laboratoire AM3, case 561, Faculté des Sciences de Saint Jérôme, 13397 Marseille Cedex \\ 20, France \\ E-mail: jean-marc.mattalia@univ.u-3mrs.fr
}

\section{Dedicated to Professor Marcial Moreno-Mañas on the occasion of his $60^{\text {th }}$ birthday}

(received 14 Jan 02; accepted 28 Mar 02; published on the web 05 Apr 02 )

\begin{abstract}
A new, very fast aryl radical clock, the 2-bromophenyl 3-phenyl-2-propenyl ether 1, was reacted with $n$-BuLi in THF. A large amount of cyclized product was formed. Such a product could have arisen from an efficient cyclization of a radical formed by dissociation of the radical anion yielded by an ET to 1. Evolution with time, temperature effects and deuteration results, strongly hint, however, that the mechanism of this exchange reaction is rather of the polar type $\left(\mathrm{S}_{\mathrm{N}} 2\right.$ or "ate complex") in agreement with previous reports from the literature based on evidences gained by other types of approaches. The carbanionic cyclization described here is one of the fastest ever reported.
\end{abstract}

Keywords: Aryl bromide-alkyllithium exchange, n-butyllithium, radical probe

\section{Introduction}

The bromide-lithium exchange reaction is a powerful method for the preparation of organolithium compounds. ${ }^{1}$ In terms of mechanisms, there seems to be a dichotomy between alkyl and aryl halides for this reaction. For alkyl halides some experimental evidence (ESR, NMR, rearranged and secondary products) hint at the participation of radical intermediates whereas some others (stereochemistry) suggest the opposite. The situation has been summarized and critically discussed in Bailey and Patricia's review. ${ }^{2}$ For aryl halides, a polar mechanism seems far more generally accepted. Wittig ${ }^{3,4}$ and Gilman ${ }^{5}$ postulated a nucleophilic displacement 
at the halide either under its $\mathrm{S}_{\mathrm{N}} 2$ form or its "ate complex" form. Beak and co-workers 6,7 rationalized their isotope labeling experiments on aryl bromides by the involvement of $\mathrm{S}_{\mathrm{N}} 2$ or of ate complexes and discarded both an ET and a four-center concerted mechanism. Such ate complexes were detected by Reich and co-workers 8,9 and Ogawa et a ${ }^{10}$ for iodoaromatics. More recently Boche and co-workers carried out comprehensive ab initio electronic structure calculations on $\mathrm{Ph}-\mathrm{I}-\mathrm{CH}_{3}(-)$ and other ate complexes. ${ }^{11}$ Their predictions for the relative thermodynamic stabilities of ate anions strongly suggest that such ate structures may be key intermediates (or transition states) in halogen-lithium exchange reactions.

For aryl halides, data suggesting the intervention of an ET in the halogen metal exchange reaction are provided by Bickelhaupt group. ${ }^{12,13}$ The bromobenzene involved has, however, a special structure: its halogen is "enclosed" in a metacyclophane structure linked in ortho and ortho' positions to the halogen. This situation very probably drastically diminishes the accessibility of the halogen with respect to the nucleophilic attack.

In the reaction between organic halides and metallic magnesium an apparent dichotomy is also observed between alkyl halides and aryl halides. The use of free radical probes repeatedly showed the intervention of alkyl radicals in the reaction of alkyl halides-magnesium. ${ }^{14-18}$ In contrast, when relatively "slow" radical probes were used in THF for exploring the reaction between aryl halides and magnesium the quantity of cyclized product suggested that very little ET, if any, was involved in the reaction. ${ }^{19,20}$ This quantity, however, increased considerably on changing the solvent from THF to diethyl ether ${ }^{20}$ and when faster free radical clocks, specifically designed, were used ${ }^{21}$ (although one recent data from the literature is at variance with these observations ${ }^{22}$ ). Therefore, to explore if the absence of ET contribution in the aryl bromidealkyllithium exchange reaction was apparent (i.e. formation of an aryl radical reduced into a carbanion very rapidly) or real, we decided to investigate this reaction by an independent method. We did it by using a specially designed fast radical clock.

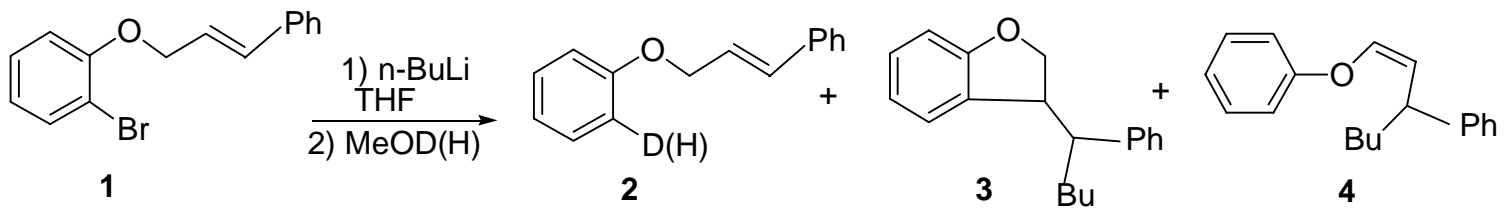

\section{Scheme 1}

The 2-bromophenyl 3-phenyl-2-propenyl ether $\mathbf{1}$ is a precursor for a radical (by loss of $\mathrm{Br}$ ) whose intramolecular rate of cyclization should be higher than $810^{9} \mathrm{~s}^{-1}$ at $30^{\circ} \mathrm{C} .{ }^{23,24}$ Indeed this rate constant was measured for an homolog radical whose double bond is not substituted by a phenyl. The stabilizing properties of a phenyl group substituting a radical are well recognized. ${ }^{16,25,26}$ Therefore the actual intramolecular rate of cyclization of the radical probe generated from 1 is probably around $10^{10} \mathrm{~s}^{-1}$. Such a rate constant should allow the detection of radical in the halogen-lithium exchange reaction even if an ET transforms the radical very 
rapidly into a non cyclizable carbanion. It is the aim of the present report to show that, indeed, when $\mathbf{1}$ is submitted to the bromide-lithium exchange reaction, good amounts of cyclized products may be formed at $-80^{\circ} \mathrm{C}$. But, here, the critical analysis of the whole set of experiments rather suggests that an ET is not involved and that the simple polar mechanism $\left(\mathrm{S}_{\mathrm{N}} 2\right.$ or ate complex) rationalizes better the observed facts.

\section{Results and Discussion}

The reaction of $\mathbf{1}$ with $n$-BuLi in THF leads to the formation of three products, noted as $\mathbf{2}, \mathbf{3}$ and 4 (Scheme 1). The relative yields are highly dependent on the reaction conditions. Throughout this work, each experiment was performed at least twice, and reproducible yields $( \pm 5 \%)$ of products 2, 3 and 4 were obtained.

Table 1. Reaction of $\mathbf{1}$ with $n$-BuLi in THF at $-80^{\circ} \mathrm{C}$

\begin{tabular}{ccccc}
\hline Entries & Time $(\min )$ & \multicolumn{3}{c}{ Relative Yields $(\%)^{b}$} \\
\hline & & $\mathbf{2}$ & $\mathbf{3}^{c}$ & $\mathbf{4}$ \\
\cline { 2 - 5 } $\mathbf{1}$ & 5 & $90^{d}$ & 5 & 5 \\
$\mathbf{2}$ & 30 & 70 & 17 & 13 \\
$\mathbf{3}$ & 60 & 39 & 46 & 15 \\
\hline
\end{tabular}

${ }^{a}$ To a solution $0.05 \mathrm{M}$ in 1 was added 1.5 eq. of $n$-BuLi. The mixture was quenched at $-80^{\circ} \mathrm{C}$ after the indicated time. ${ }^{b}$ Relative yields determined by NMR and GC. ${ }^{c} 60 \%$ de. ${ }^{d} \% \mathrm{D}>95 \%$ estimated from NMR and GC-MS

Table 1 summarizes the results obtained for the reaction of 1 with $n$-BuLi at $-80^{\circ} \mathrm{C}$ quenched at different reaction times by addition of MeOD. At this temperature, in 5 minutes the Li-Bromine exchange reaction is over. This very high reactivity converges with previous reports: the addition of two equivalents of $t$ - BuLi (in pentane) to a solution of a terminal vinyl bromide in the Trappsolvent mixture 27 at $-120^{\circ} \mathrm{C}$ resulted in an essentially quantitative yield of the desired vinyllithium compound. ${ }^{28}$ Entry 1 shows that, at $-80^{\circ} \mathrm{C}, 5 \%$ of cyclized compound $\mathbf{3}$ is formed. $\mathbf{3}$ may be considered as the result of at least three successive reactions: one $\mathrm{S}_{\mathrm{N}} 2$ leading to $\mathbf{2 a}$, one cyclization and one alkylation by $n-\mathrm{BuBr}$ (co-product of $\mathbf{2 a}$, Scheme 2). It would be five successive reactions (Scheme 3) if the initial 


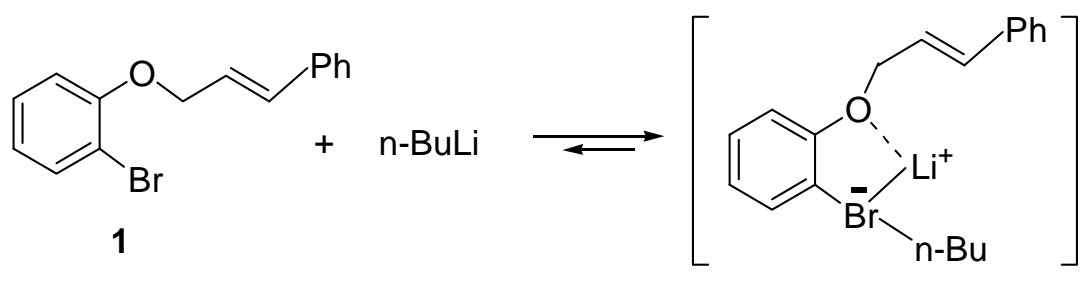

$1 \mathbf{a}$

ate complex or $\mathrm{SN}_{2} \mathrm{~T}$.S.
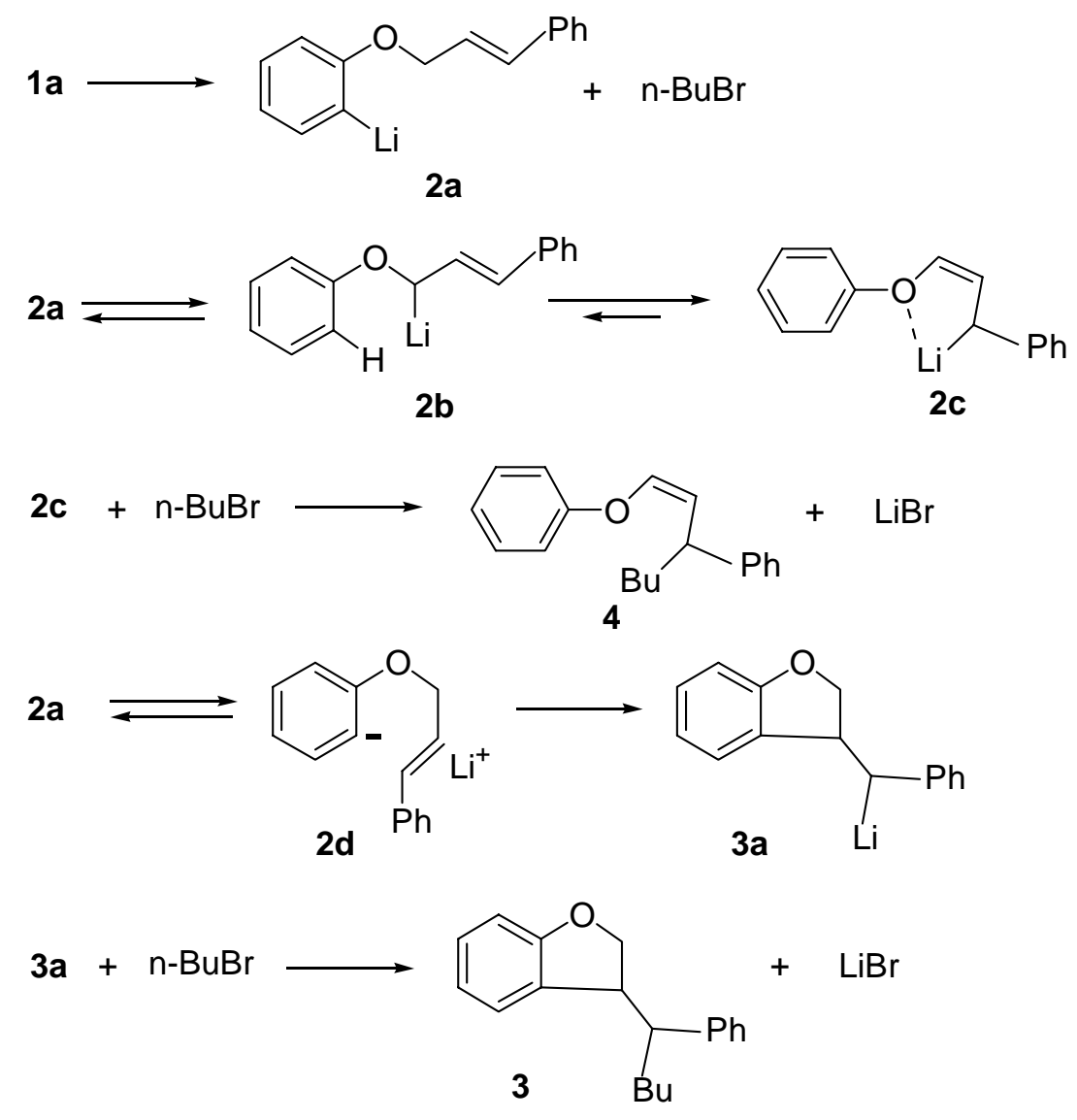

Scheme 2. $\mathrm{S}_{\mathrm{N}} 2$ or ate complex mechanism.

act of reaction was an ET from $n$-BuLi to $\mathbf{1}$; this would lead to a radical anion yielding an aryl radical intramolecularly trapped by the double bond and the cyclized radical could then couple with $n-\mathrm{Bu}^{\bullet}$ to yield $\mathbf{3}$.

The following points strongly suggest that Scheme 2 better accounts for the experimental data than Scheme 3: first, the amount of $\mathbf{3}$ increases when the primarily formed 2a is given time to react intramolecularly. The intramolecular cyclization of organolithium compounds has sometimes given rise to contradictory results. For example, Bailey and co-workers have reported that the cyclization of 6-hepten-2-yllithium (the secondary alkenyllithium derived from 6-iodo-1heptene) is apparently complete within a few minutes at $-78^{\circ} \mathrm{C} .{ }^{29}$ 


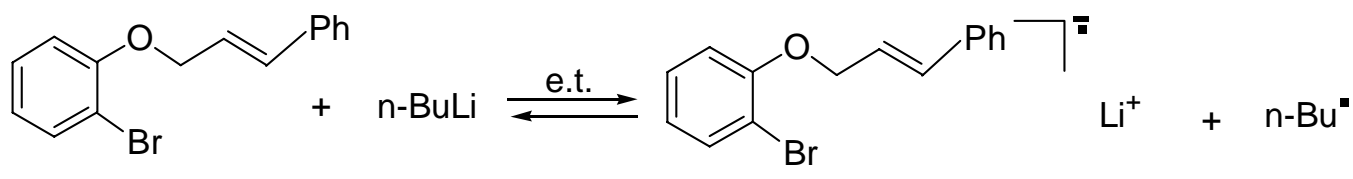

1

1b<smiles>Br[13CH](Br)c1ccccc1</smiles>

$2 e$<smiles>Clc1ccccc1OCC=Cc1ccccc1</smiles>

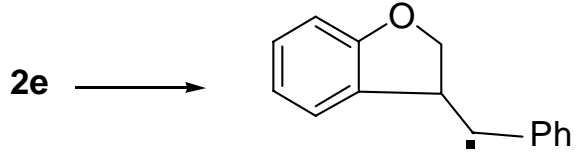

3b

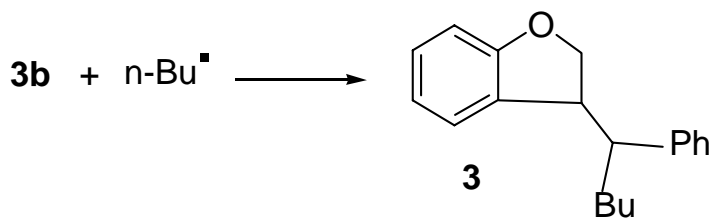

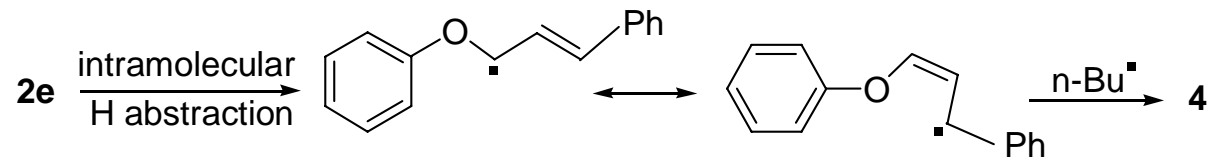

Scheme 3. ET (non chain) mechanism.

Ashby and Pham, on the other hand, reported that the cyclization of this organolithium compound is slower than that of the primary 5-hexen-1-yllithium. ${ }^{30}$ Usually, the rate of cyclization of carbanions ( $\mathrm{Mg}$ as counterion) is far smaller than the rate of the corresponding radical. ${ }^{31,32}$ For the specific case of aryl carbanions Woolsey et al showed that, at room temperature, the outcome of reaction between $n$-BuLi and o-(3-butenyl)bromobenzene is a cyclized compound. ${ }^{33}$ The rate of this cyclization considerably decreases when the $\mathrm{Li}^{+}$ counterion is replaced by $\mathrm{MgX}^{+} .20$ Walter reported that the Grignard reagent corresponding to 2a (Li replaced by $\mathrm{MgX}$ ) and unsubstituted on the exo double bond does not cyclize in refluxing diethyl ether. ${ }^{22}$

The rather important percentage of cyclization $(46 \%)$ at $-80{ }^{\circ} \mathrm{C}$ (Entry 3, Table 1) for $2 \mathbf{a}$ hints therefore at an important counterion effect possibly complemented by a stabilization of the carbanion in the cyclic form thanks to the phenyl group. Indeed, the very fact that after 5 minutes at $-80{ }^{\circ} \mathrm{C}$ the dominant product is $\mathbf{2 a}$ (Entry 1, Table 1) discards the possibility that 2a is formed via $2 \mathbf{e}$. It is so because the rate of cyclization of $\mathbf{2 e}$ is so high that the rate of the reaction between $2 \mathrm{e}$ and $n-\mathrm{BuLi}$ would have to be beyond the diffusion limit to explain the formation of 18 times more 2a than 3. To confirm the assumption that cyclization of carbanion 2a occurs, we examined the effect of increasing the temperature. Table 2 summarizes the drastic effect of the 
temperature: warming the reaction mixture leads to complete isomerization of $\mathbf{2 a}$ into $\mathbf{3 a}$ in only 5 minutes at temperatures $\geq-50{ }^{\circ} \mathrm{C}$.

Table 2. Effect of temperature on the reaction of 1 with $n$-BuLi in THF

\begin{tabular}{ccccc}
\hline Entries & Temp. $\left({ }^{\circ} \mathrm{C}\right)$ & \multicolumn{3}{c}{${\text { Relative Yields }(\%)^{b}}^{b}$} \\
\cline { 2 - 5 } $\mathbf{1}$ & & $\mathbf{2}$ & $\mathbf{3}$ & $\mathbf{4}$ \\
$\mathbf{2}$ & -80 & $90^{c}$ & 5 & 5 \\
$\mathbf{3}$ & -70 & 37 & 53 & 10 \\
$\mathbf{4}$ & -50 & 0 & 86 & 14 \\
\hline
\end{tabular}

${ }^{a}$ To a solution $0.05 \mathrm{M}$ in 1 was added 1.5 eq. of $n$-BuLi. The lithium compounds were prepared at $-85^{\circ} \mathrm{C}$ after $5 \mathrm{~min}$, the mixture is allowed to reach the indicated temperature and stand for 5 min. before quenching with MeOD at the same temperature. ${ }^{b}$ Relative yields were determined by NMR and GC. ${ }^{c} \% \mathrm{D}>95 \%$ as estimated from NMR and GC-MS.

Secondly, when the radical probe 1 was used to study the possible participation of radical intermediates in the formation of aryl Grignard reagents a different pattern of reactivity was observed. ${ }^{21}$ Besides the cyclized Grignard reagent corresponding to $\mathbf{3}$ but formed by a radical cyclization, the final mixture contains also $15 \%$ of phenol and $o$-bromophenol. These products are absent in the reaction of $n-\mathrm{BuLi}$ with $\mathbf{1}$. Their formation may be rationalized by a partition of the radical anion character (or-equivalently-to a rapid intramolecular electron transfer from one aromatic ring to the other) between the two aromatic rings present in the structure of $\mathbf{1}$. The initial formation of a radical anion in the succession of steps leading to the aromatic Grignard reagent seems well accepted. ${ }^{34}$

Thirdly, when Ward studied the metal-halogen interchange with the radical probe 6-bromo1-phenyl-1-hexyne reacting with $n$-BuLi in hexane/diethyl ether ( $5: 1$ by volume) he reached the conclusion that at least part of the reaction was involving ET. ${ }^{35}$ In Ward's publication, $\mathrm{D}_{2} \mathrm{O}$ was used to hydrolyse the reaction mixture, deuterium was found in only $7 \%$ of the linear hydrocarbon and $25 \%$ of the cyclized one. In our case, the reaction of 1 with $n$-BuLi in THF leads to a high deuterium content in $\mathbf{2}$ (Entry 1, Table 1).

In this first approach, regarding the by-product 4, NMR of the isolated product and GC-MS of the crude mixture revealed no deuterium incorporation at the carbon ortho to the OR group (nevertheless, the accuracy of GC-MS and NMR does not exclude a minor D content). We propose in Scheme 2 that 4 could be formed via intramolecular rearrangement of the carbanionic intermediate 2a with the allylic protons, forming a delocalized ambident anion. The benzylic carbanion 2c, more abundant, would then react with $n$-BuBr. The (Z)-stereochemistry of 4 can be rationalized because the intermediate $2 \mathrm{c}$ is stabilized by $\mathrm{Li} / \mathrm{Oxygen}$ coordination. The formation of (Z)-N-(1-propenyl)benzamide recently observed in the reaction of $\mathrm{N}$-allylbenzamides and $n$ BuLi has been explained by a similar coordination of the lithium atom to the nitrogen atom at the 
$\gamma$-carbon. ${ }^{36}$ For the ET mechanism (Scheme 3) the same pathway can not be applied because $n$ $\mathrm{BuBr}$ should not be present in the medium (except if $n$-Bu react with 1 in an $\mathrm{S}_{\mathrm{H}} 2$ reaction). An intramolecular hydrogen abstraction in 2e could lead to 4 . Such a pathway, however, does not explain the (Z)-stereochemistry of 4.

All these observations converge to suggest that the reaction of $n-\mathrm{BuLi}$ with $\mathbf{1}$ involves a substitution on bromine with an ate type complex as fleeting intermediate or transition state. The cyclization of the carbanionic intermediate derived from 2-bromophenyl 3-phenyl-2-propenyl ether 1 at $-80{ }^{\circ} \mathrm{C}$ is probably one of the fastest carbanionic cyclization ever reported. Two possible rationalizations of the rapidity could be offered: one centered on the $\mathrm{O}$ atom connecting the allyl chain to the aryl ring, the other centered on the phenyl substituent on the exocyclic double bond. A possible insight about this couple of questions could be provided by considering the energies of open forms versus cyclized ones. In homogeneous series the most exothermic reaction could be the fastest one (Hammond postulate). Comparing the couple of $\Delta \mathrm{E}$ values for 5-8 versus 6-9 (Figure 1) shows that, apparently, the cyclization displays almost the same exothermicity for $\mathrm{X}=\mathrm{O}$ and $\mathrm{X}=\mathrm{CH}_{2}$ when the organolithium compounds are considered. The same holds true for the carbanionic counterparts (see 11-14 versus 12-15). The phenyl substituent on the exo double bond seems to play a more important role in the exothermicity of the reaction. Whereas the couple 5-8 hints at an exothermicity of $16.3 \mathrm{kCal} \mathrm{mol}^{-1}$ for the cyclization, this exothermicity reaches $20.7 \mathrm{kCal} \mathrm{mol}^{-1}$ for the couple $\mathbf{7 - 1 0}$. The comparaison of couples 11-14 and 13-16 shows an even clearer stabilization of the cyclized form brought by the phenyl group on the double bond.
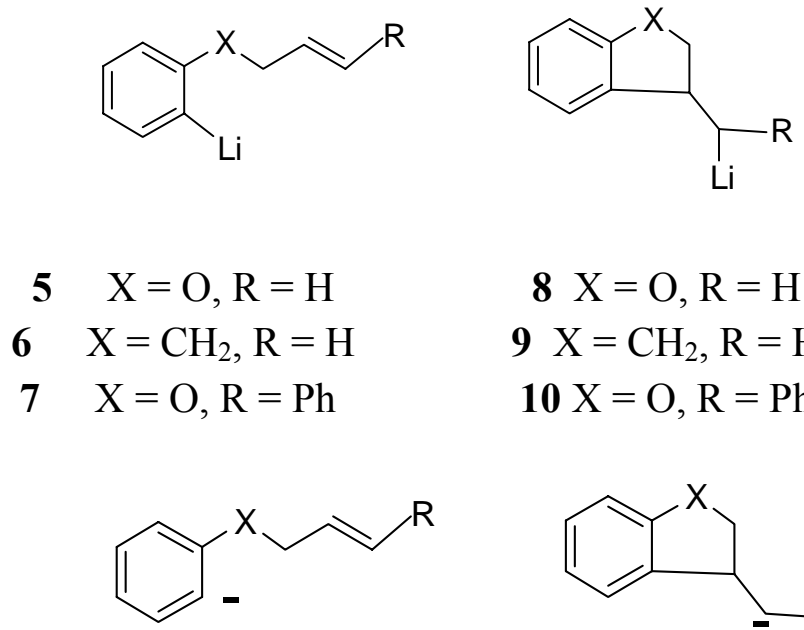

$$
8 \mathrm{X}=\mathrm{O}, \mathrm{R}=\mathrm{H}
$$$$
9 \mathrm{X}=\mathrm{CH}_{2}, \mathrm{R}=\mathrm{H}
$$$$
10 X=\mathrm{O}, \mathrm{R}=\mathrm{Ph}
$$

$$
\begin{array}{cc}
5 & \mathrm{X}=\mathrm{O}, \mathrm{R}=\mathrm{H} \\
6 & \mathrm{X}=\mathrm{CH}_{2}, \mathrm{R}=\mathrm{H} \\
7 & \mathrm{X}=\mathrm{O}, \mathrm{R}=\mathrm{Ph}
\end{array}
$$

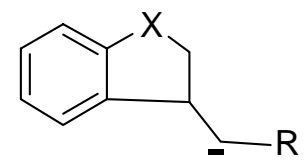

$14 \mathrm{X}=\mathrm{O}, \mathrm{R}=\mathrm{H}$

$15 \mathrm{X}=\mathrm{CH}_{2}, \mathrm{R}=\mathrm{H}$

$16 \mathrm{X}=\mathrm{O}, \mathrm{R}=\mathrm{Ph}$ 
E (hartrees)

$\mathrm{E}$ (hartrees)

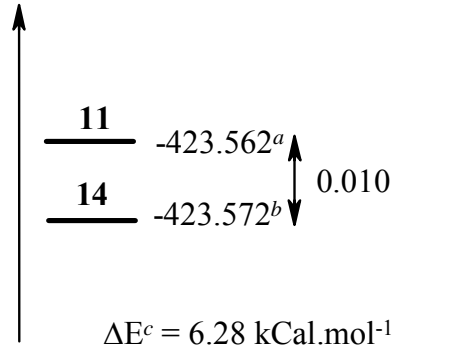

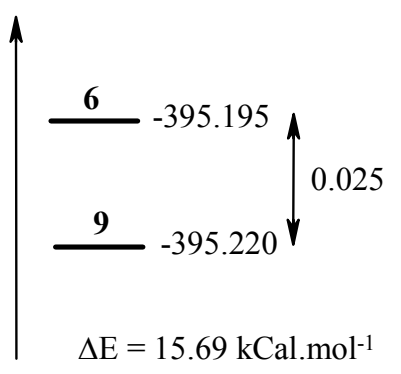
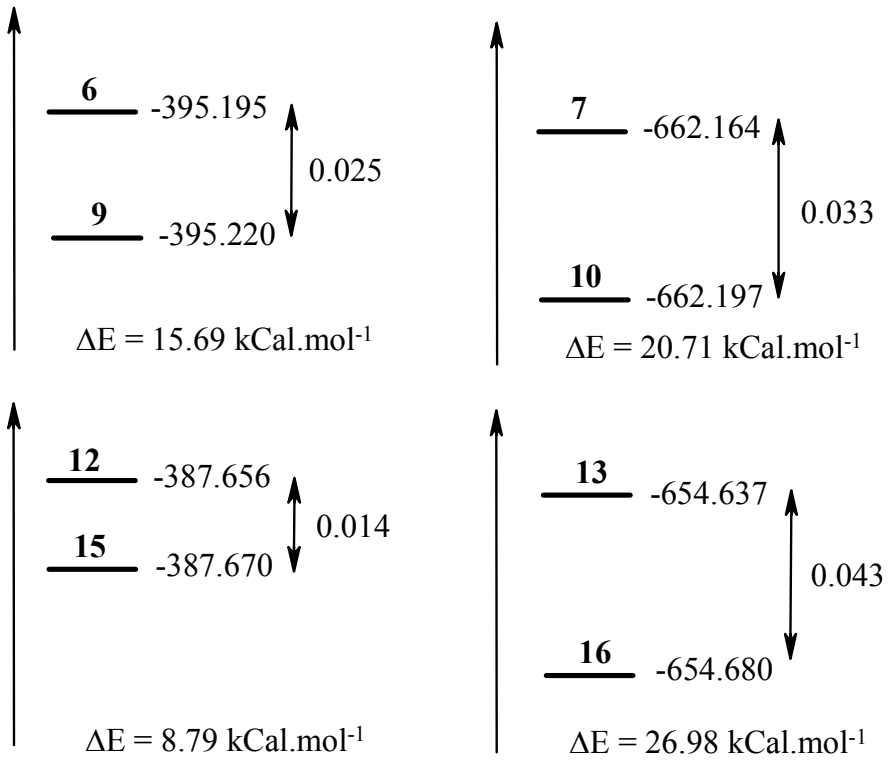

${ }^{a} \mathrm{E}+$ zpe (11) $=-423.410$ hartrees. ${ }^{b} \mathrm{E}+$ zpe $(\mathbf{1 4})=-423.419$ hartrees. ${ }^{c} \Delta(\mathrm{E}+$ zpe $)=5.65$ $\mathrm{kCal} . \mathrm{mol}^{-1}$.

zpe : zero point energy correction

Figure 1. Computed energies of structures 5-16. See Experimental Section.

In the introduction we recalled that some reports propose an ET mechanism participation in the halogen-lithium exchange reaction, whereas others propose an $S_{N} 2$ type or ate complex for this reaction. The consideration of standard electrode potentials of alkyl halides and aryl halides could help in rationalizing the reactivities covering both alkyl and aryl halides. $\mathrm{E}^{\circ}\left(\mathrm{RX} / \mathrm{R}^{*} \mathrm{X}^{-}\right)$for alkyl halides in acetonitrile are around $-1.5 \mathrm{~V}$ vs NHE. ${ }^{37}$ Those of aryl halides are around -2.3 V. ${ }^{38} n-\mathrm{BuLi}$, as a reducing agent, should therefore react faster with alkyl halides than with aryl halides. This agrees with the general trend that aryl halides generally react via $\mathrm{S}_{\mathrm{N}} 2$ or ate mechanism rather than by ET. On the other hand, for alkyl halides, the iodides, which are the best electron acceptors in the series $\mathrm{F}, \mathrm{Cl}, \mathrm{Br}$, I are also, by far, the most prone to form ate-type complexes. ${ }^{8-10}$ As a consequence the ET participation in the reactivity of alkyl iodides is generally not observed (see, however, ref. 30). The situation is more complex for alkyl bromides because, here, ET and $\mathrm{S}_{\mathrm{N}} 2$ rates are in the same range. Therefore playing with medium (dielectric constant, salt effects) or structural effects ${ }^{39,40}$ may push the mechanism either in the polar $\left(\mathrm{S}_{\mathrm{N}} 2\right)$ or ET direction. A further complication being that large excess of alkyllithium reagent may rapidly reduce the radical intermediates primarily formed deceptively hinting, therefore an $\mathrm{S}_{\mathrm{N}} 2$ type mechanism when an ET is actually the primary reactive act. ${ }^{30}$ 


\section{Experimental Section}

General Procedures. THF was refluxed over sodium benzophenone ketyl until a dark blue solution was obtained and then distilled immediately before use and manipulated under dry oxygen-free nitrogen. NMR spectra were made with a Brucker 300 operating at $300 \mathrm{MHz}$. The ${ }^{1} \mathrm{H}$ chemical shifts are referenced relative to TMS. GC analyses were carried out on a 5890 Hewlett-Packard gas chromatograph, using a HP-5 column. GC-MS (70 eV) was carried out on a gas chromatograph-mass spectrometer QP 5050A Shimadzu. n-Butyllithium (solution in hexane) was prepared as previously described ${ }^{41}$ and titrated by the method of Watson prior to use. ${ }^{42}$ 2-Bromophenyl 3-phenyl-2-propenyl ether 1 was prepared by reaction of 2bromophenolate with cinnamyl bromide in acetone as previously described (yield $82 \%$ ). mp 55$6{ }^{\circ} \mathrm{C}$ (Ethanol). ${ }^{21,43}$ An authentic sample of phenyl 3-phenyl-2-propenyl ether 2 was prepared according to literature. ${ }^{44}$

\section{General procedure for the reaction of 1 with $\mathbf{n}-\mathrm{BuLi}$}

A solution of $0.5 \mathrm{mmol}$ of 1 in $10 \mathrm{~mL}$ of THF $(0.05 \mathrm{M})$ was cooled to $-85^{\circ} \mathrm{C}$ under a blanket of dry nitrogen and 1.5 eq. of $n$-BuLi as a solution in hexane was added dropwise via syringe over a 1-2 min. period. The temperature was maintained at $-80{ }^{\circ} \mathrm{C}$ during a chosen time and reaction mixture was quenched with $0.2 \mathrm{~mL}$ of $\mathrm{MeOD}$. The reaction mixture was washed with aqueous $\mathrm{NH}_{4} \mathrm{Cl}$ solution, extracted with $\mathrm{Et}_{2} \mathrm{O}$, and dried $\left(\mathrm{MgSO}_{4}\right)$. The organic layer was analyzed by gas chromatography and ${ }^{1} \mathrm{H}-\mathrm{NMR}$. GC-MS was performed for a reaction time of 5 minutes.

Reaction of 1 with $\mathbf{n}$-BuLi at various temperatures. The organolithium derivative from $\mathbf{1}$ was generated as previously described. After $5 \mathrm{~min}$. at $-80^{\circ} \mathrm{C}$, the reaction mixture was allowed to reach the desired temperature and stand for $5 \mathrm{~min}$. before quenching with MeOD and usual work-up.

Identification of compounds. Products 2, 3 and $\mathbf{4}$ were isolated from crude mixtures. A first column chromatography on silica-gel (petroleum ether $40-65{ }^{\circ} \mathrm{C}$ and $1 \%$ ethyl acetate in petroleum ether $40-65{ }^{\circ} \mathrm{C}$ as eluents) afforded compound $\mathbf{4}$ and a mixture of 2 and 3. Column chromatography on silica-gel impregnated with silver nitrate (1\% ethyl acetate in petroleum ether $40-65{ }^{\circ} \mathrm{C}$ as eluent) afforded samples of $\mathbf{3}$ and 2 . Additional chromatography can be necessary to obtain pure samples.

\section{General protocol for silica-gel impregnated with silver nitrate}

In a 1 litre flask equipped with a magnetic stirrer was introduced silver nitrate $(2.5 \mathrm{~g})$ and acetonitrile $(150 \mathrm{~mL})$. After stirring in the dark (10 min.), silica-gel (50 g, 230-400 mesh) was added. The mixture was stirred 2 hours in the dark and then the solvent was evaporated. Drying was achieved overnight in an oven.

Phenyl 3-phenyl-1-heptenyl ether 4 ( $\mathrm{Z}$ isomer). ${ }^{1} \mathrm{H}-\mathrm{NMR}\left(300 \mathrm{MHz}, \mathrm{CDCl}_{3}\right) \delta 0.86$ (t, 3H, $J=$ $6.6 \mathrm{~Hz}), 1.20-1.40(\mathrm{~m}, 4 \mathrm{H}), 1.64-1.80(\mathrm{~m}, 2 \mathrm{H}), 3.94(\mathrm{~m}, 1 \mathrm{H}), 4.97(\mathrm{dd}, 1 \mathrm{H}, J=10.0$ and $6.0 \mathrm{~Hz})$, $6.40(\mathrm{~d}, 1 \mathrm{H}, J=6.0 \mathrm{~Hz}), 6.97-7.06(\mathrm{~m}, 3 \mathrm{H}), 7.15-7.34(\mathrm{~m}, 7 \mathrm{H}) .{ }^{13} \mathrm{C}-\mathrm{NMR}\left(75 \mathrm{MHz}, \mathrm{CDCl}_{3}\right) \delta$ 
$14.18,22.74,29.86,36.37,40.50,116.54,117.21,122.65,126.06,127.46,128.54,129.68$, 139.90, 145.69, 157.65. GC-MS m/z (rel. ab.): 266(3) [ $\left.\mathrm{M}^{+}\right]$, 209(49), 115(100). Anal. Calcd. for $\mathrm{C}_{19} \mathrm{H}_{22} \mathrm{O}: \mathrm{C}, 85.67 ; \mathrm{H}, 8.32$. Found: $\mathrm{C}, 85.02 ; \mathrm{H}, 8.16$. The $(\mathrm{Z})$-structure was deduced from the NMR coupling constants. 45

3-(1-phenylpentyl)-2,3-dihydro-1-benzofuran (3). 3 is obtained as a mixture of two diastereoisomers a and b. ${ }^{1} \mathrm{H}-\mathrm{NMR}\left(300 \mathrm{MHz}, \mathrm{CDCl}_{3}\right) \delta 0.76-0.82(\mathrm{~m}, 6 \mathrm{H}), 0.98-1.35(\mathrm{~m}, 8 \mathrm{H})$, $1.58-1.78(\mathrm{~m}, 3 \mathrm{H}), 1.90-2.01(\mathrm{~m}, 1 \mathrm{H}), 2.68-2.77\left(\mathrm{~m}, 1 \mathrm{H}_{\mathrm{a}}\right.$ and $\left.1 \mathrm{H}_{\mathrm{b}}\right), 3.54(\mathrm{td}, J=8.7$ and $4.0 \mathrm{~Hz}$, $\left.1 \mathrm{H}_{\mathrm{a}}\right), 3.68\left(\mathrm{~m}, 1 \mathrm{H}_{\mathrm{b}}\right), 4.18\left(\mathrm{dd}, 1 \mathrm{H}_{\mathrm{a}}, J=9.0\right.$ and $\left.4.1 \mathrm{~Hz}\right), 4.28\left(\mathrm{t}, 1 \mathrm{H}_{\mathrm{a}}, J=9.0 \mathrm{~Hz}\right), 4.44\left(\mathrm{dd}, 1 \mathrm{H}_{\mathrm{b}}, J\right.$ $=9.0$ and $6.3 \mathrm{~Hz}), 4.62\left(\mathrm{t}, 1 \mathrm{H}_{\mathrm{b}}, J=9.0 \mathrm{~Hz}\right), 6.25(\mathrm{~d}, J=7.4 \mathrm{~Hz}, 1 \mathrm{H}), 6.59(\mathrm{~m}, 1 \mathrm{H}), 6.74(\mathrm{~m}, 2 \mathrm{H})$, $6.86(\mathrm{~m}, 1 \mathrm{H}), 7.01-7.33(\mathrm{~m}, 13 \mathrm{H}) .{ }^{13} \mathrm{C}-\mathrm{NMR}\left(75 \mathrm{MHz}, \mathrm{CDCl}_{3}\right) \delta 14.07,14.11,22.75,22.85$, 29.58, 29.63, 32.66, 33.24, 48.04, 48.15, 50.06, 50.51, 75.26, 75.72, 109.45, 109.88, 119.98, $120.08,125.58,126.19,126.58,126.74,128.28,128.51,128.55,128.59,128.67,129.23,129.67$, 143.11, 143.22, 160.44, 160.67. GC-MS m/z (rel.ab.): 266(2) [ $\left.\mathrm{M}^{+}\right], 119(100)$, 91(88). Anal. Calcd. for $\mathrm{C}_{19} \mathrm{H}_{22} \mathrm{O}$ : C, 85.67; H, 8.32. Found: C, 85.60; H, 8.34.

Phenyl 3-phenyl-2-propenyl ether $\mathbf{d}_{1} 2$ (E isomer). mp 67.5-68.5 ${ }^{\circ} \mathrm{C} .{ }^{1} \mathrm{H}-\mathrm{NMR}(300 \mathrm{MHz}$, $\left.\mathrm{CDCl}_{3}\right) \delta 4.70(\mathrm{dd}, 2 \mathrm{H}, J=5.7$ and $1.3 \mathrm{~Hz}), 6.42(\mathrm{dt}, 1 \mathrm{H}, J=15.8$ and $5.7 \mathrm{~Hz}), 6.74(\mathrm{~d}, 1 \mathrm{H}, J=$

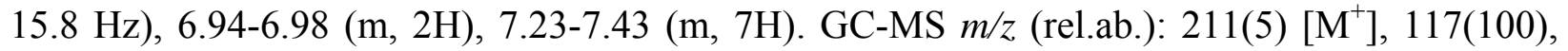
115(83), $91(60)$.

Computational methodology. The quantum chemistry calculations were carried out using the Gaussian98 program package. ${ }^{46}$ These calculations have been performed using two methods, the $a b$ initio Hartree Fock (HF) method and density functional theory (DFT). ${ }^{47}$ Geometry optimizations were carried out at restricted HF with the 6-31(d) basis set. Single point energies were computed at restricted $\mathrm{B} 3 \mathrm{LYP}^{48}$ with the polarized double zeta $6-31 \mathrm{G}+(\mathrm{d}, \mathrm{p})$ basis set. For 11 and 14, frequency calculations were performed. Zero point energies (ZPE) derived from the B3LYP frequency calculations are calculated and used to correct the relative energies.

\section{Acknowledgements}

N.B. and G. V. G. are grateful recipients of a post-doctoral fellowship from ECOS-CONICET and a fellowship from CONICET, respectively. Financial support from the Universidad de Buenos Aires and CONICET are gratefully acknowledged.

\section{References}

1. Wakefield, B. J. Organolithium Methods; Academic Press: London, 1988.

2. Bailey, W. F.; Patricia, J. J. J. Organomet. Chem. 1988, 352, 1.

3. Wittig, G.; Schöllkopf, V. Tetrahedron 1958, 3, 91. 
4. Wittig, G. Angew. Chem. 1958, 70, 65.

5. Sunthankar, S. V.; Gilman, H. J. Org. Chem. 1951, 16, 8.

6. Beak, P.; Allen, D. J.; Lee, W. K. J. Am. Chem. Soc. 1990, 112, 1629.

7. Beak, P.; Allen, D. J. J. Am. Chem. Soc. 1992, 114, 3420.

8. Reich, H. J.; Phillips, N. H.; Reich, I. L. J. Am. Chem. Soc. 1985, 107, 4101.

9. Reich, H. J.; Green, D. P.; Phillips, N. H. J. Am. Chem. Soc. 1991, 113, 1414.

10. Ogawa, S.; Masutomi, Y.; Erata, T.; Furukawa, N. Chem. Lett. 1992, 2471.

11. Boche, G.; Schimeczek, M.; Cioslowski, J.; Piskorz, P. Eur. J. Org. Chem. 1998, 1851.

12. Jenneskens, L. W.; de Boer, H. J. R.; de Wolf, W. H.; Bickelhaupt, F. J. Am. Chem. Soc. 1990, 112, 8941. See also Ref. 13.

13. Hirano, S.; Hara, H.; Hiyama, T.; Fujita, S.; Nozaki, H. Tetrahedron 1975, 31, 2219.

14. Bodewitz, H. W. H. J.; Blomberg, C.; Bickelhaupt, F. Tetrahedron 1975, 31, 1053.

15. Ashby, E. C.; Oswald, J. J. Org. Chem. 1988, 53, 6068.

16. Hill, E. A.; Harder, C. L.; Wagner, R.; Meh, D.; Bowman, R. P. J. Organomet. Chem. 1986, $302,5$.

17. Kündig, E. P.; Perret, C. Helv. Chim. Acta 1981, 64, 2606.

18. Péralez, E.; Négrel, J.-C.; Chanon, M. Tetrahedron 1995, 51, 12601.

19. Chanon, M.; Négrel, J.-C.; Bodineau, N.; Mattalia, J.-M.; Péralez, E. Macromol. Symp. 1998, 134, 13.

20. Garst, J. F.; Boone, J. R.; Webb, L.; Lawrence, K. E.; Baxter, J. T.; Ungváry, F. Inorg. Chim. Acta 1999, 296, 52.

21. Bodineau, N.; Mattalia, J.-M.; Timokhin, V.; Handoo, K.; Négrel, J.-C.; Chanon, M. Org. Lett. 2000, 2, 2303.

22. Walter, R. I. J. Org. Chem. 2000, 65, 5014.

23. Johnston, L. J.; Lusztyk, J.; Wayner, D. D. M.; Abeywickreyma, A. N.; Beckwith, A. L. J.; Scaiano, J. C.; Ingold, K. U. J. Am. Chem. Soc. 1985, 107, 4594.

24. Garden, S. J.; Avila, D. V.; Beckwith, A. L. J.; Bowry, V. W.; Ingold, K. U.; Lusztyk, J. J. Org. Chem. 1996, 61, 805.

25. Peters, D. G. In Organic Electrochemistry; Lund, H.; Baizer, M. M., Eds; Dekker, M.: NewYork, 1991; Ch. 8, p. 372.

26. Newcomb, M.; Choi, S.-Y.; Horner, J. H. J. Org. Chem. 1999, 64, 1225.

27. Köbrich, G.; Trapp, H. Chem. Ber. 1966, 99, 680.

28. Neumann, H.; Seebach, D. Tetrahedron Lett. 1976, 4839.

29. Bailey, W. F.; Nurmi, T. T.; Patricia, J. J.; Wang, W. J. Am. Chem. Soc. 1987, 109, 2442.

30. Ashby, E. C.; Pham, T. N. J. Org. Chem. 1987, 52, 1291.

31. Richey, H. G., Jr.; Rees, T. C. Tetrahedron Lett. 1966, 4297.

32. Kossa, W. C., Jr.; Rees, T. C.; Richey, H. G., Jr. Tetrahedron Lett. 1971, 3455.

33. Ross, G. A.; Koppang, M. D.; Bartak, D. E.; Woolsey, N. F. J. Am. Chem. Soc. 1985, 107, 6742 . 
34. Garst, J. F.; Ungváry, F. In Grignard Reagents: New Developments; Richey, H. G., Jr., Ed.; Wiley: Chichester, 2000; Ch. 7, p 222.

35. Ward, H. R. J. Am. Chem. Soc. 1967, 89, 5517.

36. Ribéreau, P.; Delamare, M.; Célanire, S.; Quéguiner, G. Tetrahedron Lett. 2001, 42, 3571.

37. Eberson, L. Electron Transfer Reactions in Organic Chemistry; Springer-Verlag: Berlin, 1987; pp 119-121.

38. Andrieux, C. P.; Savéant, J.-M. J. Am. Chem. Soc. 1993, 115, 8044.

39. Bailey, W. F.; Patricia, J. J.; Nurmi, T. T. Tetrahedron Lett. 1986, 27, 1865.

40. Ashby, E. C.; Pham, T. N.; Park, B. Tetrahedron Lett. 1985, 26, 4691.

41. Nudelman, N. S.; García Liñares, G. E. J. Org. Chem. 2000, 65, 1629.

42. Watson, S. C.; Eastham, J. F. J. Organomet. Chem. 1967, 9, 165.

43. Moody, C. J.; Doyle, K. J.; Elliott, M. C.; Mowlem, T. J. J. Chem. Soc., Perkin Trans. 1 1997, 16, 2413.

44. White, W. N.; Fife, W. K. J. Am. Chem. Soc. 1961, 83, 3846.

45. Matoba, K.; Motofusa, S.; Cho, C. S.; Ohe, K.; Uemura, S. J. Organomet. Chem. 1999, 574, 3.

46. Frisch, M. J.; Trucks, G. W.; Schlegel, H. B; Scuseria, G. E.; Robb, M. A.; Cheeseman, J. R.; Zakrzewski, V. G.; Montgomery, Jr., J. A.; Stratmann, R. E.; Burant, J. C.; Dapprich, S.; Millam, J. M.; Daniels, A. D.; Kudin, K. N.; Strain, M. C.; Farkas, O.; Tomasi, J.; Barone, V.; Cossi, M.; Cammi, R.; Mennucci, B.; Pomelli, C.; Adamo, C.; Clifford, S.; Ochterski, J.; Petersson, G. A.; Ayala, P. Y.; Cui, Q.; Morokuma, K.; Malick, D. K.; Rabuck, A. D.; Raghavachari, K.; Foresman, J. B.; Cioslowski, J.; Ortiz, J. V.; Baboul, A. G.; Stefanov, B. B.; Liu, G.; Liashenko, A.; Piskorz, P.; Komaromi, I.; Gomperts, R.; Martin, R. L.; Fox, D. J.; Keith, T.; Al-Laham, M. A.; Peng, C. Y.; Nanayakkara, A.; Gonzalez, C.; Challacombe, M.; Gill, P. M. W.; Johnson, B.; Chen, W.; Wong, M. W.; Andres, J. L.; Gonzalez, C.; Head-Gordon, M.; Replogle, E. S.; Pople, J.A. GAUSSIAN98; Gaussian, Inc., Pittsburgh PA, 1998.

47. Parr, R. G.; Yang, W. Density-Functional Theory of Atoms and Molecules; Oxford Univ. Press: Oxford, 1989.

48. Becke, A. D. J. Chem. Phys. 1993, 98, 5648. 